\title{
A new species of Ormyridae (Hymenoptera: Chalcidoidea) parasitizing a gall-making weevil on twigs of the bunge hackberry tree in China
}

\author{
Yan-xia Yao \& Zhong-qi Yang*
}

Yao, Y. \& Yang, Z. 2004: A new species of Ormyridae (Hymenoptera: Chalcidoidea) parasitizing a gall-making weevil on twigs of the bunge hackberry tree in China. - Entomol. Fennica 15: 142-148.

Ormyrus coccotori sp. n. (Hymenoptera: Chalcidoidea: Ormyridae) is described from China. It is a bivoltine larval ectoparasitoid of Coccotorus chaoi Chen (Coleoptera: Curculionidae) that is a serious pest in most parts of China as a gallmaker on twigs of the bunge hackberry tree Celtis bungeana Blume (Ulmaceae). This is the first ever report of a member of Ormyridae being parasitic of weevils. $O$. coccotori thus has potential for biological control of the weevil. Type specimens are deposited in the Insect Collection Museum of the Chinese Academy of Forestry.

Yao Yan-xia and Yang Zhong-qi, Research Institute of Forest Protection, Chinese Academy of Forestry, Haidian District, Beijing 100091, China; *Corresponding author's e-mail: yangzq@forestry.ac.cn,yaoyxzd@hotmail.com

Received 30 June 2003, accepted 24 November 2003

\section{Introduction}

Chen (1993) recently described Coccotorus chaoi Chen (Coleoptera: Curculionidae) from China. This weevil occurs throughout most of China from the provinces of Guangdong to Liaoning and makes galls on the twigs of the bunge hackberry tree Celtis bungeana Blume (Ulmaceae) (Wang 1992). In many areas the galls occur on nearly all twigs of the attacked trees (Fig. 1) and greatly influence tree growth. The weevil is considered a severe pest, as bunge hackberry is an important ornamental tree in China. A survey of beneficial parasitoids of the weevil was conducted between 1997 and 2000 in a search for biological control agents for management of the pest. Several parasitoids were recovered, of which a species of Ormyridae (Hymenoptera: Chalcidoidea) represented $30 \%$ and
9.2\% of the parasitoids reared from Beijing City and the Shandong Province, respectively.

The Ormyridae is composed of three genera, the cosmopolitan genus Ormyrus Westwood and two monotypic genera, Eubeckerella Narendran (1999) from Malaysia and Ormyrulus Boucek (1986) from India. Narendran (1999) keyed the three genera and revised the Indo-Australian species of Ormyrus, including four species known from China. After study of the specimens reared from $C$. chaoi, we conclude that these represent another new species of Ormyrus from China.

Of the 122 described species of Ormyrus with known hosts, all are gall makers belonging to the families Cynipidae, Eurytomidae, Pteromalidae (Hymenoptera), Agromyzidae, Cecidomyiidae, Tephritidae (Diptera) or Thripidae (Thysanoptera) (Narendran 1999, Noyes 2002). Hosts of Eubeckerella are unknown, but Ormyrulus are 


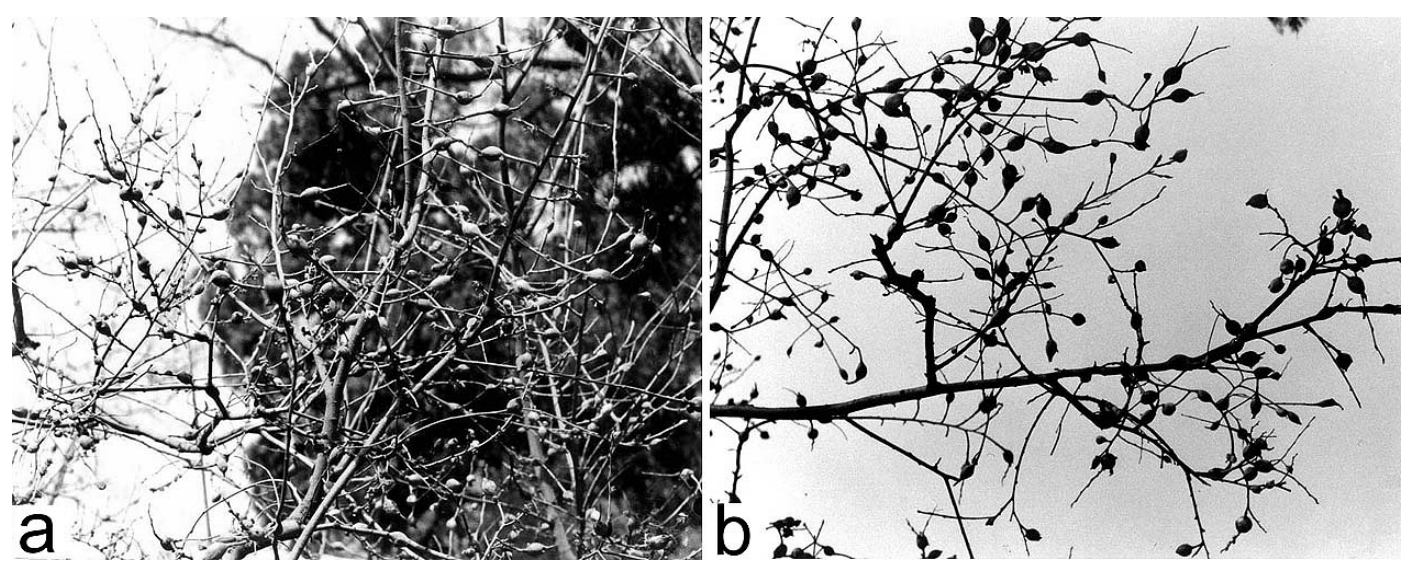

Fig. 1. Galls made by Coccotorus chaoi on twigs of Celtis bungeana.

parasitoids of a gall midge (Diptera: Cecidomyiidae) (Boucek 1986). Consequently, the new species described herein is the first record of an ormyrid parasitizing a gall-making weevil. It may have high potential as a biological control agent of the weevil pest.

\section{Material and methods}

The material studied was reared from galls of Coccotorus chaoi on twigs of Celtis bungeana. Over 1500 galls were collected from Fragrant Hill Park, Beijing, and Changqing, Shandong Province, and placed in glass jars for rearing in the laboratory. Specimens were examined with a Motic SMZ-140 stereo microscope and a Hitachi S-450 was used to obtain scanning electron photomicrographs of the parasitoid. Morphological terms used follow Boucek (1988) and Hanson (1992). Type material of the new species is deposited in the Insect Collection Museum of the Chinese Academy of Forestry.

\section{Description, biology and distri- bution of Ormyrus coccotori sp. n.}

\section{Ormyrus coccotori Yao \& Yang, sp. n. (Figs. 2-9)}

Etymology. The species epithet is derived from the generic name of its only known host.

Material examined. Holotype $\bigcirc$ : Fragrant

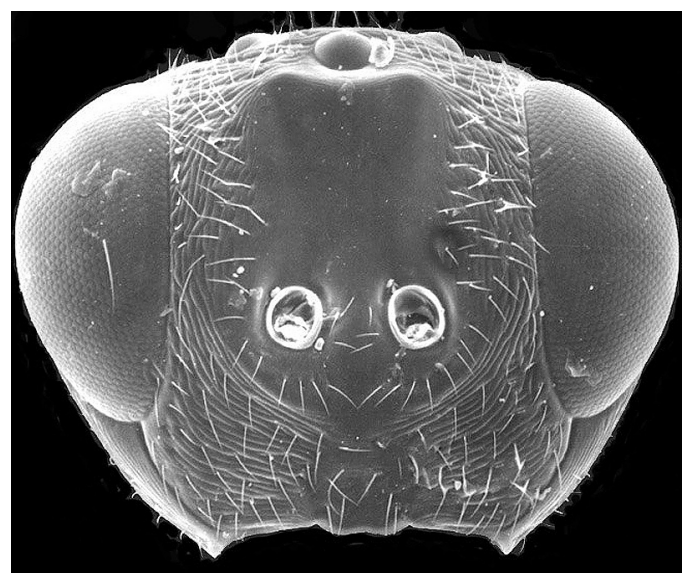

Fig. 2. Ormyrus coccotori sp. n. Female, front view.

Hill Park, Beijing, Yao Yan-xia, Yang Zhong-qi and Feng Ya-li Co., 25 April 2002, ex galls of Coccotorus chaoi on twigs of Celtis bungeana. Paratypes: 67 q, 37 के with same data as holotype; 75 , $46 \hat{\jmath}$ with same data as holotype except collection date 24 April 2001; 20 \%, $10 \hat{\jmath}$, Changqing, Shandong Province, Zhao Dai and Yao Yan-xia Co., 15 May 1997, ex galls of same host.

Description. Female: Body length 4.2-6.2 $\mathrm{mm}$. Body golden green except as follows: antenna fuscous with green metallic tint on scape; coxae and femora of same color as body; trochanters dark brown; fore leg with tibia brown dorsally but knee, apex and ventral half, and tarsus, yellow-brown; mid leg with basal half of tibia yellow and apical half fuscous, mesotibial spur and mesotarsus light yellow except tip of tarsus 


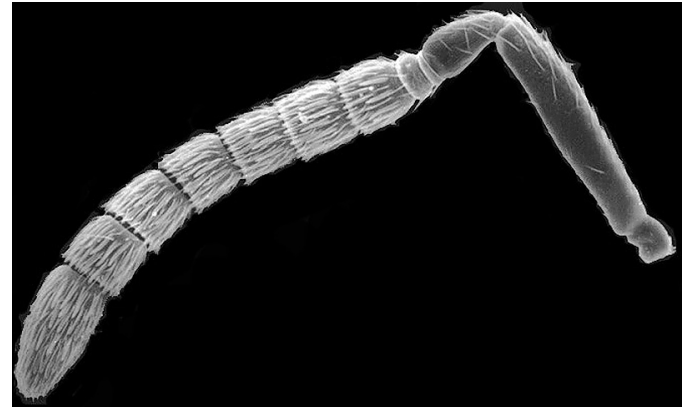

Fig. 3. Ormyrus coccotori sp. n. Female antenna.

brownish; the tibia of hind leg brown, having two spurs concolor with tibia, and hindtarsus light yellow; wings hyaline with brown venation.

Head in dorsal view about 0.9 times as wide as mesosoma and 2.1-2.2 times as wide as long, length of temple 0.25 height of eye, and POL 2.4 times OOL; occipital carina weak and extending ventrally to about midway between vertex and foramen magnum; vertex transversely strigate. Head in frontal view (Fig. 2) 1.3 times as wide as high; distance between eyes about 1.3 times own height; antennal toruli situated above ventral margin of eyes; clypeus trapezoid with anterior margin slightly produced and sub-truncate; malar space 0.46 times height of eye; antennal scrobes moderately large, shallow and polished, dorsal margin not touching median ocellus, separated from ocellus by distance about equal to diameter of ocellus; lower face with distinct, close strigae arranged in a semicircle, these being broken at clypeus, the area between antennal toruli and strigae smooth; face, parascrobal area, and vertex with sparse hairs and shallow piliferous punctures.

Antenna (Fig. 3) with scape 0.7 times the height of the eye, apex extending to level equal with dorsal margin of antennal scrobes, and with a longitudinal keel along its ventral margin; length of pedicel plus flagellum 0.9 times width of head; pedicel 1.7 times as long as wide; first anellus lamellate, second anellus twice as long as first anellus and 1.7 times as wide as long; flagellum stout, compact, with each funicular segment quadrate and of about same length; clava with segments poorly separated, length equal to that of combined length of two preceding funicular segments and not wider than funicle.

Mesosoma (Fig. 4) in lateral view with dorsal surface strongly convex, resulting in anterior margin of pronotum being in line with ventral margin of gaster (Fig. 4a); mesosoma in lateral

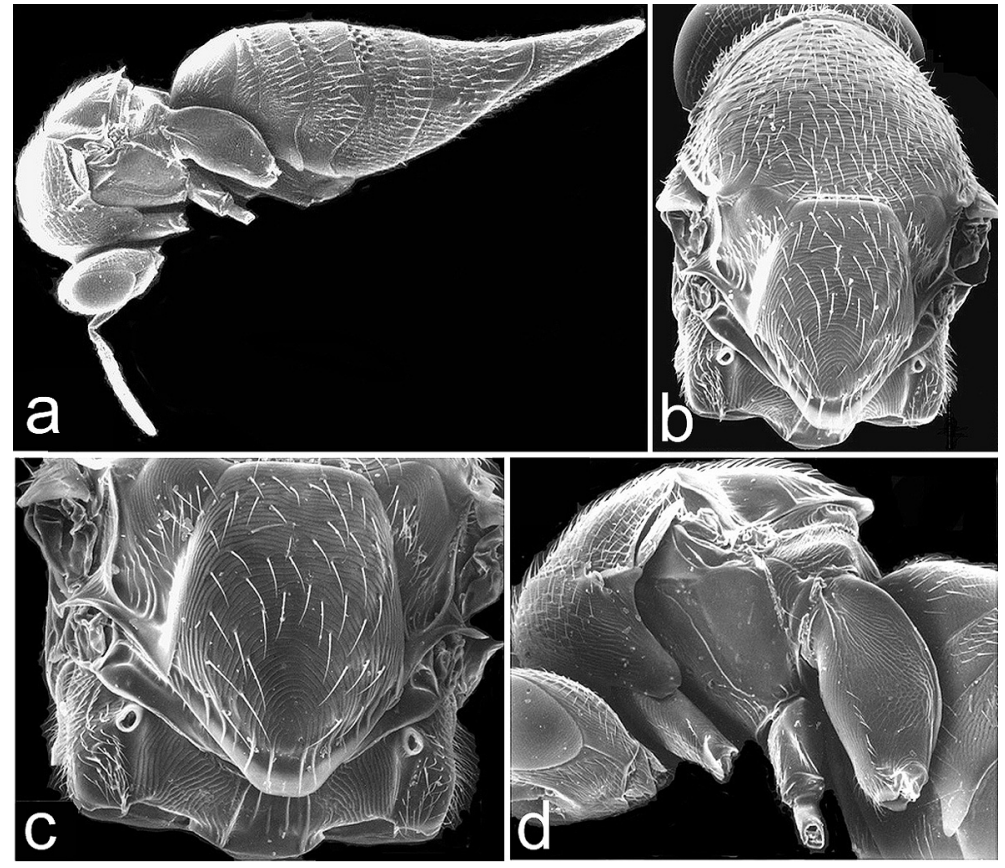

Fig. 4. Ormyrus coccotori sp. n., female. - a. Body, lateral view. - b. Mesonotum and propodeum, dorsal view. $-\mathrm{c}$. Scutellum and propodeum, dorsal view. - d. Head and mesosoma, lateral view. 


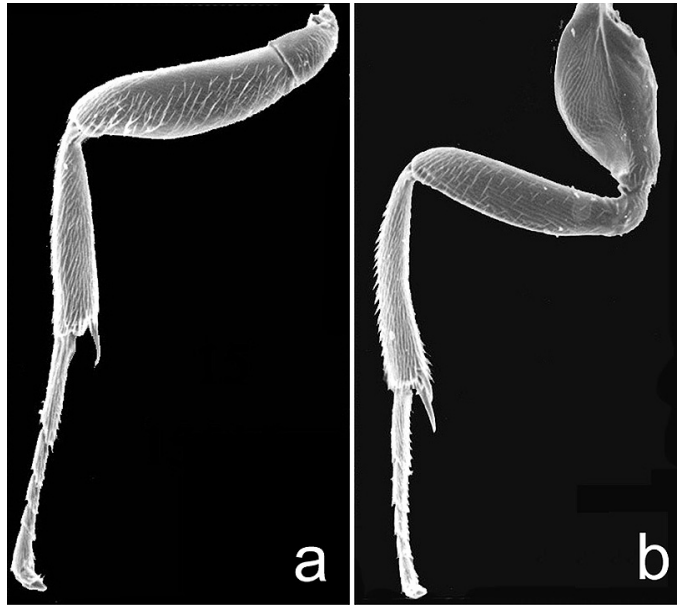

Fig. 5. Ormyrus coccotori sp. n., female. - a. Fore leg without coxa. - b. Hind leg.

view 1.3 times as long as high and in dorsal view 1.3 times as long as wide. Pronotum and mesoscutum with hairs and dense, transverse strigae. Pronotum about 0.3 times as long as mesonotum, collar gradually inclined from neck without pronotal carina, and with posterior margin emarginate medially. Mesonotum (Fig. 4b) 1.3 times as wide as long; notauli shallow but percurrent; scutellum 1.35 times as long as wide, about as long as mesoscutum, with dense hairs and with strigae arranged in a semicircle towards the median posterior margin, rounded posteriorly and with a prominent, lamella-like flange having about 10 longitudinal carinae, the flange about $1 / 8$ as long as scutellum and projecting over propodeum (Fig. 4c). Mesopleuron smooth and polished but anteriorly with distinct, complete, oblique pleural ridge (Fig. 4d). Metapleuron with vertically arranged strigae.

Propodeum steeply sloping, with two submedian carinae diverging posteriorly, the carinae surrounding a polished median area with several weak, oblique carinae; laterally with oblique, longitudinal strigae; spiracular sulcus deep and complete; spiracle elliptical and situated at anterior margin; callus with dense short hairs, the hairs clearly shorter than those on mesoscutum and scutellum, and with posterior half strongly convex so as to form large tubercle at posterolateral corner.

Front leg with basitarsus as long as combined

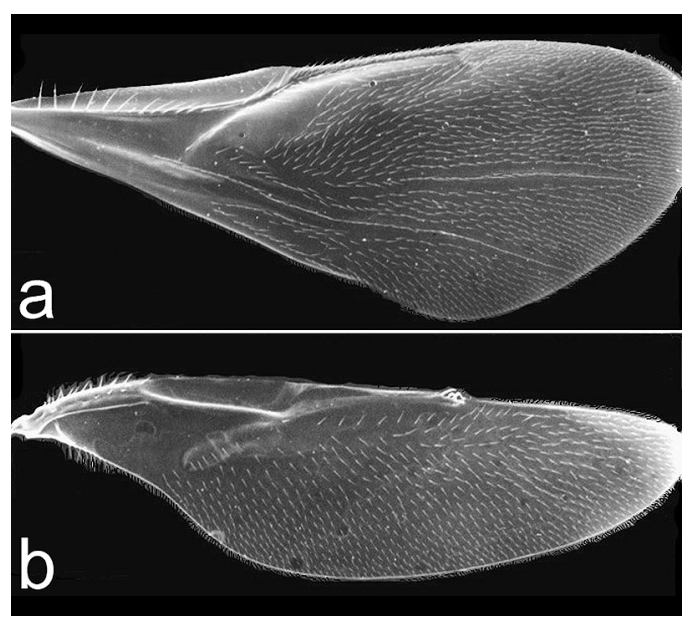

Fig. 6. Ormyrus coccotori sp. n., female. - a. Fore wing. $-b$. Hind wing.

length of three subsequent segments (Fig. 5a). Middle leg with basitarsus 1.2 times as long as combined length of two subsequent segments, and with mesotibial spur 0.6 times length of basitarsus. Hind leg with large metacoxa having oblique strigae in basal half and reticulate sculpture in apical half, and with sharp keel along dorsal margin (Fig. 4d); metafemur with ventral margin forming a narrow flange and with two curved metatibial spurs, the inner spur twice as long as outer spur and 0.7 times as long as basitarsus; basitarsus as long as combined length of two subsequent segments (Fig. 5b).

Fore wing (Fig. 6a) with costal cell having two complete rows of hairs on ventral surface near anterior margin, more densely pubescent in apical third, but dorsal surface bare; submarginal vein with 26-31 setae, mostly 28; basal cell closed and basal vein with 7-9 setae, cubital vein with 2-3 setae distally and bare proximally, with a row of 6-12 hairs within basal cell on ventral surface; speculum narrow and closed posteriorly by hairs indicating cubital vein, and with small, sparsely scattered hairs on ventral surface; forewing disc with bare band separating marginal vein from otherwise densely pubescent dorsal surface of disc; relative length of submarginal: marginal: stigmal: postmarginal veins $=76: 46: 7$ : 10; stigma falciform with a distinct petiole. Hind wing (Fig. 6b) bare behind submarginal vein, otherwise with small, pale hairs. 

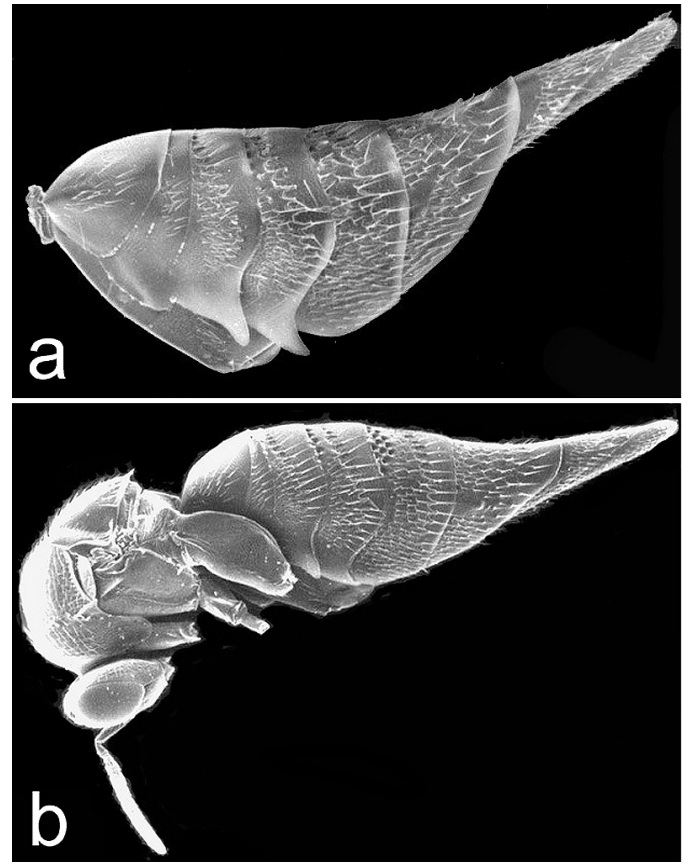

Fig. 7. Ormyrus coccotori sp. n., female. - a. Gaster, laterail view. - b. Body, lateral view.

Gaster lanceolate, acuminate and slightly compressed (Fig. 7); 2.0-2.2 times as long as combined length of head and mesosoma, in dorsal view 4.2 times as long as wide. Gastral tergites (Gt) dorsally with dense, raised reticulations, the reticulations erased in basal half to third of Gt1 and very weak along posterior margin of Gt1 and Gt2 medially; Gt1 and Gt2 with hairs laterally; Gt3-Gt5 with a dorsomedial carina and exposed large fovea located near anterior margin of respective tergite, most of the fovea usually covered by the preceeding tergite (only one row visible submedially on Gt3 and Gt4, more fovea visible on Gt5), Gt3-Gt5 also with an oblique, transverse row of longitudinal ribs, each rib apically with a prominent seta, and with smaller and more irregular ribs and scattered setae laterally; Gt6 and epipygium also with irregular ribs and setae laterally, the ribs obsolescent at posterior quarter of Gt6 and anterior fifth of epipygium; Gt6 not constricted dorsally, in lateral view dorsal margin in continuous plane with epipygium (Fig. 7); epipygium 1.7-1.8 times as long as height basally; cercus with all setae about the same length. Ovipositor sheaths protruding posteriorly. Relative lengths of Gt1-epipygium: ovipositor sheaths $=48: 10: 26: 27: 38: 64: 44: 20$. Hypopygium extending about 0.2 length of gaster.

Male (Figs. 8-9). Body length 2.4-3.5 mm, others features similar to female except as follows: antenna with apical 4 funicular segments subquadrate, slightly wider than long (10:9) (Fig. 8a); face with lower four fifth having close strigae as in female, but the upper striga carinated semicircledly; notauli percurrent but faint; gaster
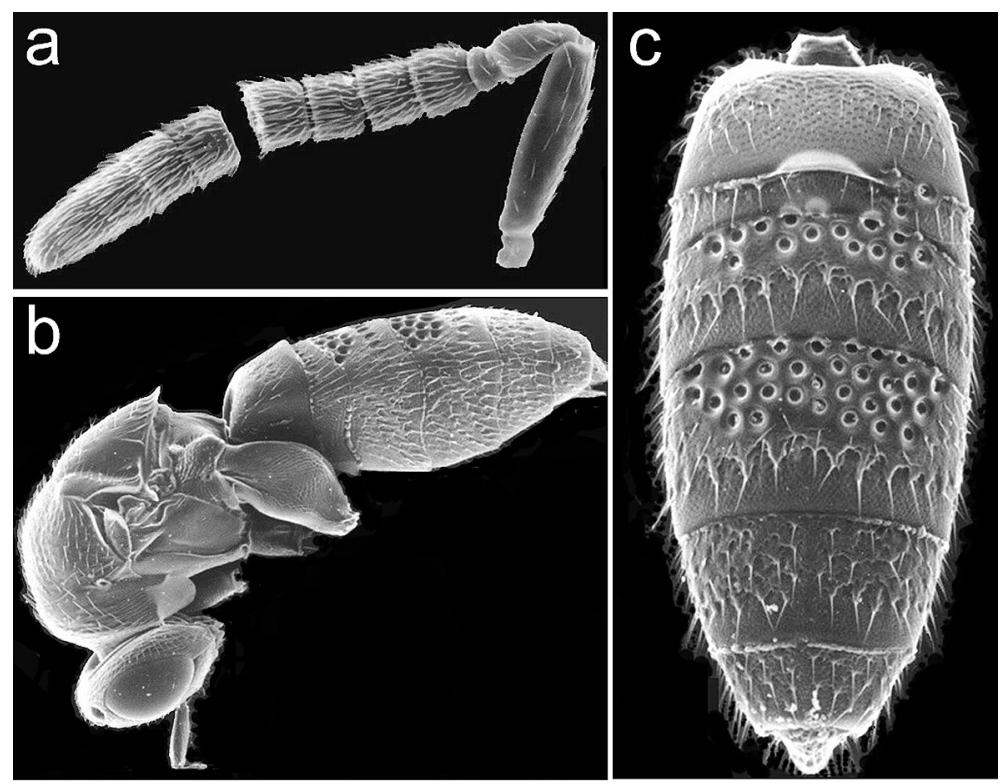

Fig. 8. Ormyrus coccotori sp. n., male. - a. Antenna. - b. Body, lateral view. - c. Gaster, dorsal view. 


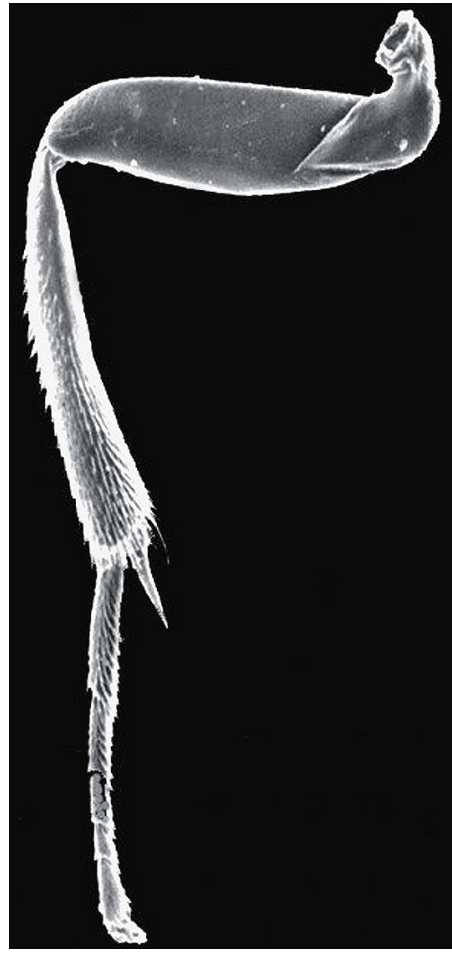

Fig. 9. Ormyrus coccotori sp. n., male hind leg without coxa.
(Fig. 8c) short, only 1.1 times combined length of head and gaster, broadly rounded laterally and slightly depressed, without dorsomedial carina, with only Gt3 and Gt4 having prominent fovea over basal third of Gt3 and almost basal half of $\mathrm{Gt} 4$, apically gaster truncate with epipygium ventral to Gt6.

Recognition. Females of $O$. coccotori key near the Japanese species $O$. flavitibialis Yasumatsu \& Kamijo (1979) in Narendran (1999), but females of the latter species differ as follows: (1) body smaller (2.5-4.3 mm) and bluish green; (2) apical funicular segment transverse and a little shorter than first segment; (3) gaster only 2.4-2.7 times as long as wide; (4) propodeum with pair of pit like depressions at posterior corners. Females of the new species are also similar to the European species $O$. nitidulus (Fabricius 1804), as keyed and illustrated by Medvedev (1978). Females of the latter species are distinguished from $O$. coccotori as follows: (1) all funicular segments notably longer than wide, and (2) gaster with penultimate tergite constricted and epipygium upturned (figure 7: 5 in Zerova \& Seryogina 1998).
Biology. This new species is the only species of Ormyrus known to have been reared from weevil galls. The species is a single koinobiont ectoparasitoid of the larva of Coccotorus chaoi. It has two generations per year and overwinters as a mature larva inside the host gall and pupates at the end of April next year. The adult of this generation emerges from late May to middle June. The newly emerged female wasp begins to mate and lays egg on the young larva of the same host species soon after emergence. After hatching the parasitoid larva attaches to its host to consume and finally kills it. The adults of the first generation emerge from early July to middle August and their offspring again are parasitic on the host larvae in a later instar. The host has one generation per year. The parasitoid larva kills its host later in October and overwinters as mature larva beside the host mummy in the gall.

Distribution. Known from Beijing and Shandong Province in China, but possibly having the same distribution as its host weevil, $C$. chaoi.

Acknowledgements. We wish to thank Dr. Gary Gibson Canadian National Collection of Insects (CNC), Agriculture and Agri-Food Canada, Ottawa, for reviewing the manuscript, and Mrs. Feng Ya-li and Mr. Zhao Dai for help in the investigation, especially with collecting the pest galls and rearing of the parasitoid.

\section{References}

Boucek, Z. 1986: Taxonomic study of Chalcidoid wasps (Hymenoptera) associated with gall midges (Diptera: Cecidomyiidae) on mango trees. - Bulletin of Entomological Research 76: 393-407.

Boucek, Z. 1988: Australasian Chalcidoidea (Hymenoptera), a biosystematic revision of genera of fourteen families, with a reclassification of species. CAB International, Wallingford, UK. 832 pp.

Chen, Y. 1993: A new species of genus Coccotorus (Coleoptera, Curculionidae: Anthonominae). - Acta Entomologica Sinica 36: 74-76. [In Chinese with English summary]

Hanson, P. 1992: The Nearctic species of Ormyrus Westwood (Hymenoptera: Chalcidoidea: Ormyridae). Journal of Natural History 26: 1333-1365.

Medvedev, G. S. 1978: Keys to the Insects of the European Part of the USSR. - Nauka Publishers, Leningrad.

Narendran, T. C. 1999: Indo-Australian Ormyridae (Hymenoptera: Chalcidoidea). - University of Calicut, Kerala, India. 227 pp. 
Noyes, J.S. 2002: Interactive Catalog of World Chalcidoidea (2001, 2. ed.). CD-ROM, the Natural History Museum and Dicky Yu.

Wang, Lin-yao, 1992: Study on the bionomics of Coccotorus chaoi Chen. - Entomological Knowledge 29: 33-35.

Yasumatsu, K. \& Kamijo, K. 1979: Chalcidoid parasites of
Dryocosmus kuriphilus Yasumatsu (Cynipidae) in Japan, with descriptions of five new species (Hymenoptera). - Esakia 14: 93-111.

Zerova, M. D. \& Seryogina, L. Ya. 1998: Chalcid wasps (Hymenoptera, Chalcidoidea). Ormyridae and Torymidae (Megastigminae) of the Ukrainian fauna. — Vestnik Zoologii Suppl. 7: 3-65. 